\title{
Predictors of Quality of Life for Pakistani Americans
}

\author{
Sidhra K. Vakil
}

University of La Verne

Glenn Gamst

University of La Verne

Lawrence S. Meyers

California State University, Sacramento

Aghop Der-Karabetian

University of La Verne

Gitu Bhatia

Private Practice

\section{Abstract}

A structural equation model with four latent variables was configured to predict Perceived Quality of Life on the part of Pakistani Americans. Based on one of the components of the Multicultural Assessment-Intervention Process (MAIP) model, Ethnic Identity was used as a predictor with Gender Role Attitudes and Muslim Religiosity hypothesized as independent mediators. A convenience sample of 351 Pakistani American adults provided the data upon which the structural model was built. Results indicated that in isolation greater levels of Ethnic Identity predicted a higher Perceived Quality of Life but, when taken into account, the latent variables of Gender Role and Muslim Religiosity each partially mediated the influence of Ethnic Identity on Quality of Life. Implications for future Pakistani American research were discussed. 


\section{Author Note}

This research partially fulfilled the requirements for the doctor of Psychology degree at University of La Verne for Sidhra K. Vakil.

Correspondence concerning this article should be addressed to Glenn Gamst, Department of psychology, University of La Verne $19503^{\text {rd }}$ Street, La Verne, CA 91750 E-mail: ggamst@laverne.edu

The present study explored Pakistani Americans' quality of life perceptions through the development of a structural equation model with ethnic identity as a predictor and gender role attitudes and Muslim religiosity as separate mediators of this relationship. Determining the critical predictive constituents of Pakistani American quality of life attitudes should help to foster more effective behavioral health service delivery and interventions to this often neglected and stereotyped Southeast Asian population (Fair, 2012; Jibeen, 2011; Qureshi \& Pacquaio, 2013).

In 2000, there were 204,000 Pakistani Americans living in the U. S. By 2015 , this figure increased to 519,000 , resulting in a $154.4 \%$ population increase. Among these individuals over 96\% identify as Muslim, with 72\% Sunnis, $6 \%$ Shias, and 22\% other Islamic sects (Pew Research Center, 2017). As this population continues to grow within the United States, coupled with events in Pakistan (e.g., capture of Osama Bin Laden), and the paucity of published empirical research on this population, the need for understanding the dynamics of Pakistani mental health and well-being is both evident and prudent (Jibeen, 2011). There has been relatively little research concerning this topic. We review the quality of life/well-being literature as it pertains to Pakistani Americans and then using the Multicultural Assessment-Intervention Process (MAIP) model, we briefly review literature on three salient constructs that appear to be related to Pakistani American quality of life attitudes.

\section{Quality of Life}

The idea of quality of life or life satisfaction involves aspects of attitudes, feelings, and behaviors related to subjective wellbeing, physical health, and everyday life functioning (Frisch, Cornell, Villaneuva, \& Retzlaff, 1992; Frisch et al., 2005; Hoffman, Wu, \& Boettcher, 2014; Platsidou, 2012; Veenhoven, 1996). Diener's (1984) early review of the quality of life literature indicated the importance of self-acceptance, family life satisfaction, and income level as important constituents of this construct.

In potentially relevant related studies in Pakistan, Suhail and Chaudhry 
(2004) examined quality of life for individuals living in Pakistan, who found that higher levels of income, marriage, and religiosity were positive predictors of quality of life. Kanwal and Mustafa (2016) reported lower levels of quality of life and wellbeing among male Pakistani physically disabled employees than their able-bodied counterparts employed in electrical facilities. Aflakseir (2012) examined the effects of religiosity on psychological wellbeing of first generation Muslim students who had migrated from Islamic countries (including Pakistan), and suggested that religiosity and spirituality were highly correlated with wellbeing. Ali (2006), exploring the impact of acculturation, religiosity, social support, and ethnic identity on the quality of life of Pakistani Americans, indicated that religiosity, ethnic identity, and social support were positively correlated with quality of life; no statistically significant correlation between acculturation and quality of life was found, suggesting Pakistani Americans who utilized more assimilated or integrated acculturation strategies (higher acculturation) may not have viewed their quality of life as being affected.

In a related study from Pakistan, Grewal, Nazroo, Bajekal, Blane, and Lewis (2004) qualitatively examined factors that led to improved quality of life among older immigrants, including immigrants from Pakistan. Grewal et al. (2004) found that Pakistani parents reported that being responsible for their children, even after marriage, was both a cultural and religious obligation; fulfillment of this perceived obligation created a higher sense of quality of life for these parents.

Due in part to the relative lack of published empirical literature on Pakistani American quality of life research, the Multicultural Assessment-Intervention Process (MAIP) model (Dana, 1993, 2000; Gamst, Liang, \& Der-Karabetian, 2011) was used to provide a cultural context to select three constructs (ethnic identity, religiosity, gender role attitudes) that could impact Pakistani American quality of life. The MAIP provides seven culturally sensitive mental health service delivery phases that have been found to positively influence behavioral health outcomes including quality of life. These MAIP components include a culturally sensitive intake contact (initial screening interview), client match preference (cultural, gender, language, etc.), multicultural status assessment (acculturation, ethnic identity, gender roles, etc.), provider self-perceived cultural competence and multicultural training, ethnic-specific and/or general interventions, and clinical outcome assessment (Gamst \& Liang, 2013). The present study focuses exclusively on the Multicultural Status Assessment phase of the MAIP, and not the entire model, because we have narrowed our focus to predictors of quality of life for this population and not to the broader issues of mental health service delivery that the entire MAIP framework elucidates.

Early empirical MAIP research examined client-practitioner ethnic/racial match (Gamst, Dana, Der-Karabetian, \& Kramer, 2000), and practitioner self- 
reported cultural competence (Gamst, Dana, Der-Karabetian et al., 2004; Keyser, Gamst, Meyers, Der-Karabetian, \& Morrow, 2015) on clinical outcome. Recent work has expanded the Multicultural Status Assessment phase to include cultural shifting as a coping mechanism for African American women (Johnson, Gamst, Meyers, Arellano-Morales, \& Shorter-Gooden, 2016), and Latina Americans (Gamst et al., 2018). Quality of life perceptions among Pakistani Americans can also be considered within this MAIP component expansion.

Through the MAIP conceptual framework and literature review, Pakistani American ethnic identity was identified as a predictor of quality of life mediated by Muslim religiosity and gender role attitudes, and these constructs were configured as latent variables in a structural equation model that examined the predictive effects of these variables on Pakistani American quality of life attitudes. These constructs are briefly reviewed in the following sections.

\section{Pakistani American Ethnic/Racial Identity}

Ethnic identity focuses on individuals' sense of affiliation with their ethnic group; conversely, racial identity emphasizes how racial minorities develop their personal schema within a context of perceived oppression (Trimble, Helms, \& Root, 2003). Both constructs share the following three commonalities: (a) they describe a sense of belonging to a social group; (b) positive and negative attitudes can be associated with one's social group; and (c) these attitudes vary across time and context (Gamst et al., 2011).

A very limited amount of published work on Pakistani and Pakistani American ethnic identity currently exists. Ibrahim, Ohnishi, and Sandhu (1997) found that racial and ethnic identity development for individuals from South Asian cultures such as Pakistan are primarily a function of their cultural traditions and religious beliefs. Recent qualitative research suggests that Pakistani Americans' ethnic identity revolves around issues of socioeconomic status, social and cultural activities, religion, discrimination, and gender relations (Ghani, 2016). These factors become particularly salient for Pakistani immigrants to the U. S. (Ibrahim \& Heuer, 2013).

A qualitative study by Hussain and Baggule, (2005) explored the link between citizenship and Pakistani identity development among first and second generation Pakistani immigrants residing in Britain. Results indicated that second generation Pakistanis connected their British citizenship to part of their overall ethnic identity, a process of combining their new British culture with their Pakistani heritage with which many of them were able to achieve effortlessly. Conversely, their first generation counterparts viewed themselves as visitors to the country and did not consider their citizenship as part of their self-concept. 
Jacobson (1997) argued that for most ethnic Pakistanis, Islam is the core of their identity and their ethnicity is viewed as a secondary factor. This suggests that the role of religion in the development of ethnic identity is salient, as religion plays a strong role in many cultural traditions and also serves as a supporting mechanism for immigrants migrating to a new country, particularly for Pakistani Muslims (Peek, 2005).

Pakistani American ethnic identity, as is the case for ethnic identity for other ethnic groups, shows a consistent pattern of effects as this relatively new ethnic population adjusts to mainstream American cultural norms. Based in part on the previous limited published research literature and expectations from the MAIP framework, it is expected that ethnic identity will positively predict Pakistani American quality of life attitudes.

\section{Pakistani American Gender Role Attitudes}

Gender role attitudes reflect socially constructed beliefs about appropriate role activities for women and men (Eagly \& Wood, 1991; McHugh \& Frieze, 1997). Two prevailing views concerning appropriate gender roles can be observed among both Pakistanis and Pakistani Americans, a liberal and conservative viewpoint (Khalid, 2011). The conservative viewpoint promotes traditional gender roles (e.g., female subordination to males) whereas liberal views promote an egalitarian and more collaborative relationship between husband and wife (Isran \& Isran, 2012).

Most of the empirical research in this regard has focused on individuals living in or having recently migrated from Pakistan. For example, a qualitative study of Pakistani women by Ali et al. (2011) observed serious gender inequalities and human rights violations including limitations of autonomy. Education and mass media were viewed as positive influences that supported women's empowerment. Similarly, Ali, Mogren, and Krantz (2013) examined mental health effects caused by intimate partner violence among women living in Karachi, Pakistan. Findings suggested that intimate partner violence occurs more often in areas where there are more gender disparities and contributes to women experiencing more mental health issues and suicidal ideation, increased feelings of worthlessness, and increased levels of depression.

Shahzadi, Qureshi, and Islam (2012) examined the views and attitudes of Pakistanis regarding domestic violence experienced by women. Results indicated that nearly $60 \%$ of respondents believed that Pakistani laws are purposely designed to thwart the rights of women (e.g., authorizing public battering of women for certain crimes). Khalid and Frieze (2004) examined differences among Muslim men and women living in Pakistan and the U.S. concerning attitudes toward women. Results indicated that men and women from the U.S. 
and Pakistan with more liberal viewpoints were less likely to condone violence towards women. Findings of gender role differences between Pakistani males and females have been attributed to early family experiences and amplified by the educational system (Raza \& Murad, 2010).

Immigration experiences have also been shown to effect gender role attitudes. Khalid (2011) explored the change in perception of gender roles for a sample of Pakistani individuals who had migrated to the United Kingdom (U.K.) for a short period and returned to Pakistan (which is common for economic and educational reasons). These individuals were compared to a group of Pakistani non-migrants. Statistically significant differences in gender role perceptions between migrant and non-migrant groups were found; individuals who had migrated to the U.K. and returned to Pakistan showed less traditional and conservative views on roles for men and women. However, it should be noted that these correlational results did not establish causality between migrant group status and gender role attitudes.

Pakistani and Pakistani American gender role attitudes are clearly learned early in life and are manifested depending upon an individual's political outlook or worldview. To date there has been no published research linking Pakistani American gender role attitudes to quality of life perceptions. Therefore, the present study examined the mediational role that gender role attitudes plays between Pakistani American ethnic identity in predicting quality of life perceptions.

\section{Pakistani American Religiosity}

Pakistani American religiosity is primarily a function of the teachings of Islam (United States Department of State, 2012) and focuses on religious activities such as prayer and spirituality or beliefs and values (Hackney \& Sanders, 2003; Holdcroft, 2006). Several investigators have examined the relationship of religiosity to an individual's quality of life. For example, Diener and Clifton (2002) observed that individuals who hold strong religious beliefs reported high levels of quality of life; conversely, those individuals who did not report holding any religious beliefs experienced the lowest levels of life satisfaction. Similarly, Henning et al. (2015) found that spirituality and religiosity were positively correlated with quality of life.

A few recent studies have examined the role of religiosity among Muslim/Pakistani Americans and Pakistanis and perceived mental health status. Ghaffar-Kucher (2011) argued that Muslim religious affiliation or "religification" is the most salient and essential core category of identity among Pakistani American youth today; in fact, many such youth prefer to define themselves through a religious (Muslim) schema as opposed to a racial or ethnic schema. 
Herzig, Roysircar, Kosyluk, and Corrigan (2013) examined the effects of religion on coping and mental health stigma among 120 Muslim students. Results suggested that having a religious presence served as a buffer between mental health stigmas and coping strategies. Analogously, Zakar, Zakar, and Krämer (2012) examined qualitatively the coping strategies utilized by female victims of intimate partner violence. Results indicated that the most beneficial form of coping came from religious affiliations.

Ismail and Desmukh (2012) explored the relationship between religiosity and mental health among Pakistani individuals. Results indicated a statistically significant negative correlation between anxiety and religiosity. Depending on the context, religiosity may also become a risk factor. Feder et al. (2013) examined the effects of PTSD on Pakistani survivors of the devastating 2005 earthquake that struck northwest Pakistan, resulting in over 250,000 deaths. Results indicated that the majority of participants reported negative religious coping and attributed the effects of the earthquake to a punishment of their sins. This may have led to increased levels of anxiety, depression, and PTSD symptoms among the survivors.

Given the centrality of the religiosity construct to Pakistani Americans, religiosity is expected to play an important role in mediating between ethnic identity and quality of life perceptions.

\section{The Present Study}

This study focuses attention on critical cultural variables assumed to influence the dynamics related to Pakistani American quality of life perceptions. Mechanisms underlying quality of life dynamics are crucial in furthering behavioral health service delivery to this population and overcoming mental health service perceived stigma. Toward this end, a structural model was developed and tested, based in part on aspects of the MAIP framework and the limited Pakistani American quality of life literature.

\section{Method}

\section{Sample and Participant Selection}

Using convenience and snowball sampling procedures, a sample of 351 participants, 231 (65.8\%) females, 120 (34.2\%) males, were recruited for this study. Most respondents identified as Pakistani (96.7\%) followed by biracial Pakistanis (3.3\%). Participants were recruited by emailing various Pakistani organizations including Your Dil San Francisco, Cal Pakistani Students Association, 
Mental Health 4 Muslims, as well as by emailing various listservs that may have had Pakistani subscribers, including American Muslim Healthcare Professionals, South Asian Psychological Networking Association, and Asian American Psychological Association. Participants were also recruited in person at various events within the Pakistani community. Prospective participants were invited to complete an online questionnaire designed to gain a better understanding of the factors that predict Pakistani Americans' quality of life attitudes. Respondents were informed (online) that their participation was voluntary and that their responses would be anonymous. The present research was approved by the university institutional review board. As an incentive, all respondents received a $\$ 5.00$ gift card for participating in the study.

Participants' age ranged from 18 to $88,(M=32.55, S D=12.61)$. Participant primary language spoken inside the home was as follows: Urdu (49.6\%), English (39.6\%), Urdu and English (5.1\%), and other languages (5.7\%). Participant primary language spoken outside of the home was either English (94.6\%) or other languages (5.4\%). Participant marital status was as follows: married (49.2\%), single $(47.6 \%)$, and other $(3.2 \%)$. Participant country of origin was the following: United States (47.9\%), Pakistan (39.0\%), India (2.8\%), Canada (2.0\%), United Kingdom (2.0\%), and other (6.3\%). Participant citizenship was either United States (95.4\%) or other (4.6\%). Generational status of participants was as follows: $51.9 \%$ identified as first generation, $47.6 \%$ as second generation, and $0.5 \%$ as third generation. Participants' education included graduate degree $(36.0 \%)$, college graduate $(39.4 \%)$, some college $(17.7 \%)$, and high school (6.9\%). Participant religious affiliation was either Muslim (94.9\%) or other $(5.1 \%)$.

\section{Measures}

The online questionnaire contained 138 items composing the following six scales, each of which had strong empirical publication records and excellent validity and reliability specifications, together with demographic questions.

\section{Demographic questions.}

The demographic questions comprised 13 items that dealt with the participants' gender, age, language spoken primarily inside and outside of home, marital status, country of birth, ethnicity, citizenship, generational status, education, and religious affiliation.

\section{Multigroup Ethnic Identity Measure-Revised.}

The Multigroup Ethnic Identity Measure-Revised (MEIM-R; Phinney \& Ong, 2007) is a 6-item self-report measure of ethnic identity. Exploration and Com- 
mitment, the two 3-item subscales were developed through exploratory and confirmatory factor analyses (Phinney \& Ong, 2007). Adequate internal consistency (Cronbach's alpha) has been reported (Phinney \& Ong, 2007) for both Exploration $(\alpha=.76)$ and Commitment $(\alpha=.78)$. Brown et al. (2014) demonstrated measurement invariance across multiple racial and ethnic groups for the MEIM-R. Items were measured on a 5-point summative response scale that ranged from 1 (strongly disagree) to 5 (strongly agree). For the present study, internal consistency values were .88 and .90 for Exploration and Commitment subscales, respectively.

\section{Islamic Attitudes Toward Women Scale.}

The Islamic Attitudes Toward Women Scale (IAWS; Khalid \& Frieze, 2004) is a 30-item unidimensional self-report measure that assesses Muslims' attitudes towards gender roles for both males and females. Items were measured on a 4-point summative response scale that ranged from 1 (strongly agree) to 4 (strongly disagree), with a higher score representing a more conservative or traditional response. This scale is an adaptation of the Attitudes Toward Women Scale (AWS; Spence, Helmreich, \& Stapp, 1974). Khalid and Frieze (2004) validated their scale on two different samples of Pakistani individuals; these samples included Pakistani immigrants living in the United States $(\alpha=.87)$ and Pakistanis living in Pakistan $(\alpha=.91)$. For the present study, internal consistency as measured by Cronbach's alpha was .89 .

\section{Muslim Attitudes Toward Religion Scale.}

The Muslim Attitudes Toward Religion Scale (MARS; Wilde \& Joseph, 1997) is a 14-item unidimensional self-report measure that assesses an individual's attitudes toward Islam. Items were measured on a 5-point summative response scale that ranged from 1 (strongly disagree) to 5 (strongly agree). Ghorbani, Watson, Ghramaleki, Morris, and Hood (2000) independently assessed the MARS and found it to be both a valid and reliable measure of Muslim religiosity. For the present study, internal consistency as measured by Cronbach's alpha was .97.

\section{Quality of Life Inventory.}

The Quality of Life Inventory (QOLI; Frisch et al., 1992) is a 32-item multidimensional self-report measure of quality of life. The QOLI is composed of two separate subscales. The QOLI-Importance subscale consists of 16 items measured on a 3-point summative response scale that ranged from 0 (not important) to 2 (very important), with higher scores indicating greater importance to overall perceived happiness. The QOLI-Satisfaction subscale consists 
of 16 items measured on a 6-point summative response scale that ranged from -3 (very dissatisfied) to 3 (very satisfied), with higher scores indicating greater life satisfaction with various facets. Frisch et al. (1992) reported Cronbach's alphas for four independent samples using the QOLI subscales that ranged between .77 and .89. For the present study, internal consistency for the QOLISatisfaction and Importance subscales was.89 and .92, respectively.

\section{Results}

\section{Descriptive Statistics}

The means, standard deviations, and internal consistency reliabilities for the scale and subscale scores are presented in Table 1 . All values were generally within the range reported in the literature. All scales and subscales reached an acceptable level of internal consistency of .88 or higher.

Correlations among several demographic variables and key measures are also depicted in Table 1. The two quality of life measures (QOLI-Satisfaction and QOLI-Importance were moderately intercorrelated $(r=.32)$ as were the MEIM-R subscales $(r=.65)$.

\section{Structural Equation Model Analysis}

The structural equation model that was configured for the present study is shown in Figure 1. The MEIM-R subscales of Exploration and Commitment were used as indicators of the latent predictor variable of Ethnic Identity, and the Importance and Satisfaction subscales of the QOLI were used as indicators of the latent outcome variable of Quality of Life. Gender Role and Muslim

Table 1. Correlation Coefficients, Means, Standard Deviations, and Alphas Among Variables Used to Predict Quality of Life Among Pakistani American Adults $(\mathrm{N}=351)$

\begin{tabular}{lccccccccccc}
\hline Variable & $\mathbf{1}$ & $\mathbf{2}$ & $\mathbf{3}$ & $\mathbf{4}$ & $\mathbf{5}$ & $\mathbf{6}$ & $\mathbf{7}$ & $\mathbf{8}$ & $M$ & $S D$ & $\alpha$ \\
\hline 1. QOLSAT & - & $.32^{\star \star}$ & $.22^{\star \star}$ & $.32^{\star \star}$ & $.23^{\star \star}$ & .08 & $-.26^{\star \star}$ & -.04 & 4.77 & .85 & .89 \\
2. QOLIMP & & - & $.27^{\star \star}$ & $.22^{\star \star}$ & $.39^{\star \star}$ & $.28^{\star \star}$ & -.08 & .08 & 2.59 & .36 & .92 \\
3. Explore & & & - & $.65^{\star \star}$ & $.33^{\star \star}$ & $.15^{\star \star}$ & -.08 & .10 & 3.68 & .99 & .88 \\
4. Commit & & & & - & $.39^{\star \star}$ & $.16^{\star \star}$ & $-.24^{\star \star}$ & .06 & 3.87 & .91 & .90 \\
5. Religiosity & & & & & - & .03 & $.15^{\star \star}$ & -.01 & 4.00 & 1.01 & .97 \\
6. Genrole & & & & & & - & -.06 & $.15^{\star \star}$ & 4.08 & .62 & .89 \\
7. Generation & & & & & & & - & .08 & - & - & - \\
8. Gender & & & & & & & & - & - & - & -
\end{tabular}

Note: QOLSAT = QOLI-Satisfaction subscale; QOLIMP = QOLI-Importance subscale; Explore $=$ MEIM-R Exploration Subscale; Commit = MEIM-R Commitment subscale; Religiosity = MARS scale; Genrole = IAWS Scale; Generation = Participant generational status ( 1 = first generation, $2=$ second generation); Gender = Participant gender $($ male $=1$, female $=2) .{ }^{* \star} p<.01$ 


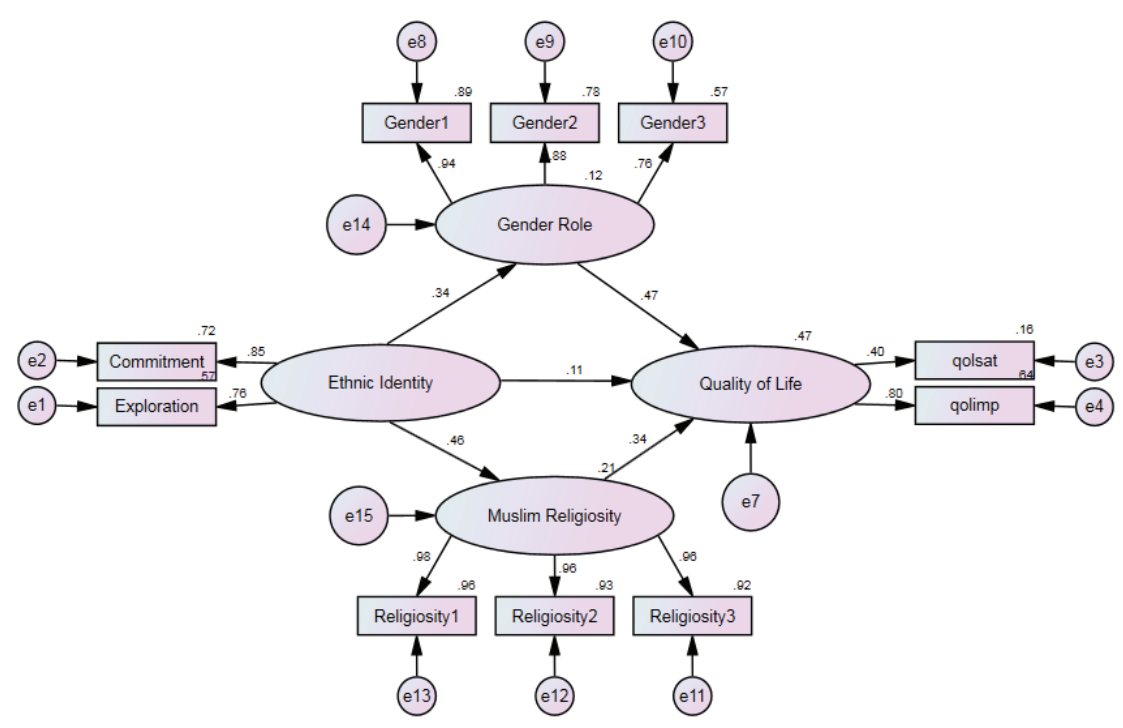

Figure 1. SEM results with standardized coefficients included $N=351$ ).

Religiosity were proposed as separate mediators of this relationship. Each of these two constructs was assessed by a single unidimensional inventory (whose structure was supported for our data set by our own preliminary principal axis factor analyses), the IAWS and the MARS, respectively. These measures were each converted into a latent variable (Coffman \& MacCallum, 2005; Kline, 2015) using item parceling (Bandalos, 2002; Bandalos \& Finney, 2001; Little Cunningham, Shahar, \& Widaman, 2002; Little, Rhemtulla, Gibson, \& Schoemann, 2013; Matsunga, 2008). Three item parcels were constructed for each construct. To achieve this parceling for each inventory, items were ordered based on their weighting on the single factor shown to represent unidimensionality for each inventory using a principal axis extraction method. Our goal was to have 4 to 5 items contained in each parcel. For the 30 items on the IAWS, the most strongly weighted 15 items were selected in blocks of three beginning with the most strongly weighted items and working downward on the list; within each set of 3 , the items were randomly distributed across the three parcels. For the 14 items on the MARS, the most strongly weighted 12 items were selected in blocks of three and randomly distributed across the three parcels in an analogous manner. These parcels then served as indicator variables for the respective latent constructs of Gender Role and Muslim Religiosity.

The model was evaluated using version 25 of IBM SPSS Amos. Although the chi square test was statistically significant, 73.896 (30, $N=351$ ), $p<.001$, the GFI was .961, the NFI was .973, the IFI was .984, the TLI was .976, the CFI was .984, and the RMSEA was .065, suggesting as a composite that the model as 
configured appeared to represent a good fit with the data. The model explained approximately $47 \%$ of the variance of Quality of Life.

The standardized coefficients are presented in Figure 1. All four of the individual paths involved in the indirect effects were separately evaluated for statistical significance. With respect to the indirect path involving Gender Role, the paths from Ethnic Identity to Gender Role (standardized coefficient $=.342$, unstandardized coefficient $=0.256$ with a standard error of $0.047, p<.001$ ) and from Gender Role to Quality of Life (standardized coefficient $=.473$, unstandardized coefficient $=0.283$ with a standard error of $0.063, p<.001$ ) were each statistically significant. An Aroian test (Aroian, 1944/1947) confirmed that this indirect path was statistically significant, $z=3.41, p<.001$.

With respect to the indirect path involving Muslim Religiosity, the paths from Ethnic Identity to Muslim Religiosity (standardized coefficient $=.450$, unstandardized coefficient $=0.600$ with a standard error of $0.082, p<.001$ ) and from Muslim Religiosity to Quality of Life (standardized coefficient $=.398$, unstandardized coefficient $=0.168$ with a standard error of $0.040, p<.001$ ) were each statistically significant. An Aroian test confirmed that this indirect path was also statistically significant, $z=3.67, p<.001$.

The direct path from Ethnic Identity to Quality of Life in the full model was not statistically significant (standardized coefficient $=.109$, unstandardized coefficient $=0.049$ with a standard error of $0.035, p=.168$ ). This lack of statistical significance together with the viability of the two indirect paths raised the possibility that we might have observed complete mediation. To evaluate this possibility, the unmediated model (Ethnic Identity to Quality of Life) was analyzed, and it was found that the path from Ethnic Identity to Quality of Life was statistically significant in that reduced model (standardized coefficient $=.556$, unstandardized coefficient $=0.373$ with a standard error of $0.071, p<.001$ ). Not surprisingly, the path in the unmediated model was significantly stronger than the direct path in the full model, $z=6.83, p<.001$. Thus, it appears that the direct relationship of Ethnic Identity to Quality of Life was entirely mediated in the full model by some combination of Gender Role and Muslim Religiosity.

To explicate the dynamics of this mediation, we separately examined the two simple mediation structures that were contained within the full model. With respect to the simple mediation structure involving Gender Role, the indirect path was statistically significant, Aroian $z=3.41, p<.001$, and of similar strength to the corresponding path in the full model. Of greater interest was the direct path from Ethnic Identity to Quality of Life; this path appeared to be less strong in magnitude to the corresponding path in the unmediated model but was statistically significant in this simple mediation model (standardized coefficient $=.274$, unstandardized coefficient $=0.121$ with a standard error of 0.039, $p=.002$ ). A Freedman-Schatzkin test (Freedman \& Schatzkin, 1992) confirmed that the strength of the direct path in this simple mediation model 
(beta $=.274)$ was significantly weaker compared to its strength in the unmediated model (beta $=.556), t(349)=6.904, p<.001$. Thus, considered in isolation, the influence of Ethnic Identity on Quality of Life was partially mediated by Gender Role.

With respect to the simple mediation structure involving Muslim Religiosity, once again the indirect path was of similar strength to the corresponding path in the full model and was statistically significant, Aroian $z=3.67, p<$ .001. As was true for the previously described simple mediation structure, of major interest here was the direct path from Ethnic Identity to Quality of Life, and this path was statistically significant in this simple mediation model (standardized coefficient $=.347$, unstandardized coefficient $=0.195$ with a standard error of $0.056, p<.001)$. A Freedman-Schatzkin test revealed that the strength of the direct path in this simple mediation model (beta $=.347$ ) was significantly weaker than its strength in the unmediated model (beta $=.556), t(349)$ $=5.427, p<.001$. Thus, considered in isolation, the influence of Ethnic Identity on Quality of Life was partially mediated by Muslim Religiosity.

To synthesize these results, it appears that Gender Role and Muslim Religiosity each partially mediated some of the influence of Ethnic Identity on Quality of Life. That is, some of the reasons for higher levels of Ethnic Identity being associated with greater levels of Quality of Life had to do with its effect on Gender Role, and other of the reasons for higher levels of Ethnic Identity being associated with greater levels of Quality of Life had to do with its influence on Muslim Religiosity. In any case, the two mediators in combination fully mediated this influence.

\section{Discussion}

A set of MAIP framework variables that included ethnic identity, gender role attitudes, and Muslim religiosity as possible predictors of Pakistani American quality of life perceptions was hypothesized. A structural model with both gender role attitudes and Muslim religiosity as mediators of ethnic identity in the prediction of Pakistani American quality of life was built. Results suggested that while ethnic identity did directly predict quality of life when considered in isolation, gender role attitudes and Muslim religiosity were observed to fully mediate the impact of ethnic identity on quality of life perceptions. Apparently, ethnic identity exerted its positive predictive impact on Pakistani American quality of life perceptions through simultaneous increases in gender role attitudes (i.e., the maintenance of more conservative or traditional viewpoints) and Muslim religiosity (i.e., greater Islamic religious orientation). Ethnic identity only becomes an indirect predictor of quality of life attitudes when both Islamic fundamentalism and traditional gender role attitudes are taken into account. 
The present findings are in accord with previous research that has established a positive relationship with Muslim religiosity and wellbeing (Aflakseir, 2012; Ali, 2006; Suhail \& Chaudry, 2004). Apparently, part of the ethnic identity of Pakistani Americans is embedded in their identification with the Muslim religion, which in turn contributes toward their experience of a higher quality of life. However, the link between Pakistani American gender role attitudes and quality of life has not been established within the literature until the present study. Previous Pakistani American gender role research has clearly differentiated between individuals holding conservative (traditional) versus liberal (egalitarian) gender role outlooks (Isran \& Isran, 2012). It appears that another part of ethnic identity relates to holding a more traditional and conservative attitude toward gender role, which in its turn separately contributes toward the experience of Pakistani Americans of a higher quality of life. Taken together, the present study demonstrates the mediational effectiveness of holding more traditional gender role attitudes while simultaneously endorsing strong Islamic religious values in conjunction with a willingness to explore (learn more about) and commit (develop a sense of belonging) to one's Pakistani American ethnic identity, both of which drive increases in quality of life perceptions.

The present study is important and has practical implications, as it contributes to our existing knowledge of Pakistani American mental health by examining factors that increase life satisfaction for this population. Understanding the predictive role of ethnic identity, gender role attitudes, and Muslim religiosity on Pakistani American QOL provides crucial knowledge for behavioral health practitioners when considering treatment planning and options for culturally sensitive interventions (Gamst et al., 2011). These results, stemming from the MAIP model, reinforce the usefulness of routinely examining these cultural factors in conjunction with QOL assessments with Pakistani Americans.

Two limitations of the present study can be noted. First, the sample was composed of relatively young adults who were college educated and recruited from social media. These individuals may not be representative of all Pakistani Americans. Second, none of the measures used in the present study were specifically designed for Pakistani Americans, and thus, may not have sensitively assessed the cultural subtleties found in this population. Nevertheless, the findings of this study are unique and important and should help guide future behavioral health service delivery to this population. The MAIP model (Dana, 1993; Gamst et al., 2011), particularly its Multicultural Status Assessment component, provided useful guidance in triangulating salient facets of Pakistani American quality of life perceptions. These results suggest that future Pakistani American quality of life research could be facilitated by utilizing some of the MAIP framework components. 


\section{References}

Aflakseir, A. (2012). Religiosity, personal meaning, and psychological well-being: A study among Muslim students in England. Pakistan Journal of Social and Clinical Psychology, 10(1), 27-31.

Ali, M. (2006). Impact of acculturation, ethnic identity, religiosity, and individual difference variables on the subjective well-being of Pakistani Muslims in the United States. (Doctoral dissertation). Retrieved from ProQuest dissertations and theses. (3229824)

Ali, T. S., Mogren, I., \& Krantz, G. (2013). Intimate partner violence and mental health effects: A population-based study among married women in Karachi, Pakistan. International Journal of Behavioral Medicine, 20, 131-139. https://doi.org/10.1007/ s12529-011-9201-6

Aroian, L. A. (1947). The probability function of the product of two normally distributed variables. Annals of Mathematical Statistics, 18, 265-271. (Original work published 1944). https://doi.org/10.1214/aoms/1177730442

Bandalos, D. L. (2002). The effects of item parceling on goodness-of-fit and parameter estimate bias in structural equation modeling. Strucural Equation Modeling, 9, 78102. https://doi.org/10.1207/S15328007SEM0901_5

Bandalos, D. L., \& Finney, S. J. (2001). Item parceling issues in structural equation modeling. In G. A. Marcoulides \& R. E. Schumacker (Eds.), New developments and techniques in structural equation modeling (pp. 269-296). Mahwah, NJ: Erlbaum.

Coffman, D. L., \& MacCallum, R. C. (2005). Using parcels to convert path analysis models into latent variable models. Multivariate Behavioral Research, 40, 235-259. https://doi.org/10.1207/s15327906mbr4002_4

Dana, R. H. (1993). Multicultural assessment perspectives for professional psychology. Needham Heights, MA: Allyn \& Bacon.

Dana, R. H. (2000). Multicultural assessment principles, applications, and examples. Mahwah, NJ: Erlbaum.

Diener, E., \& Clifton, D. (2002). Subjective well-being. Psychological Bulletin, 95(3), 542-575. https://doi.org/10.1037/0033-2909.95.3.542

Diener, E., \& Clifton, D. (2002). Life satisfaction and religiosity in broad probability samples. Psychological Inquiry, 13(3), 206-209.

Eagly, A. H., \& Wood, W. (1991). Explaining sex differences in social behavior: A meta-analytic perspective. Personality and Social Psychology Bulletin, 17, 306-315. https://doi.org/10.1177/0146167291173011

Fair, C. C. (2012). Pakistan in 2011: Ten years of the 'war on terror'. Asian survey, 52(1), 100-113. https://doi.org/10.1525/as.2012.52.1.100

Feder, A., Ahmad, S., Lee, E., Morgan, J., Singh, R., Smith, B., . . Charney, D. (2013). Coping and PTSD symptoms in Pakistani earthquake survivors: Purpose in life, religious coping and social support. Journal of Affective Disorders, 147(1-3), 156163. https://doi.org/10.1016/j.jad.2012.10.027

Freedman, L. S., \& Schatzkin, A. (1992). Sample size for studying intermediate endpoints within intervention trials of observation studies. American Journal of Epidemiology, 136, 1148-1159. https://doi.org/10.1093/oxfordjournals.aje.a116581

Frisch, M. B., Cornell, J., Villanueva, M., \& Retzlaff, P. J. (1992). Clinical validation of The quality of life inventory: A measure of life satisfaction for use in treatment planning and outcome assessment. Psychological Assessment, 4(1), 92-101. https:// doi.org/10.1037/1040-3590.4.1.92 
Frisch, M. B., Clark, M. P., Rouse, S. V., Rudd, M. D., Paweleck, J. K., Greenstone, A., \& Kopplin, D. A. (2005). Predictive and treatment validity of life satisfaction and the quality of life inventory. Assessment, 12(1), 66-78. https://doi. org/10.1177/1073191104268006

Gamst, G. C., \& Liang, C. T. H. (2013). A review and critique of multicultural competence measures: Toward a social justice-oriented health service delivery model. In F. A. Paniagua, \& A. M. Yamada (Eds.), Handbook of multicultural mental health: Assessment and treatment of diverse populations ( $2^{\text {nd }}$ ed.), ) pp. 547-569). San Diego, CA: Academic Press. https://doi.org/10.1016/B978-0-12-394420-7.00028-X

Gamst, G. C., Liang, C. T. H., \& Der-Karabetian, A. (2011). Handbook of multicultural measures. Thousand Oaks, CA: SAGE.

Gamst, G., Dana, R. H., Der-Karabetian, A., \& Kramer, T. (2000). Ethnic match and client ethnicity effects on global assessment and visitation. Journal of Community Psychology, 28(5), 547-564. https://doi.org/10.1002/1520-6629(200009)28:5<547::AIDJCOP8>3.0.CO;2-T

Gamst, G., Dana, R. H., Der-Karabetian, A., Aragon, M., Arellano, L., Morrow, G., \& Martenson, L. (2004). Cultural competency revised: The California Brief Multicultural Competence Scale. Measurement and Evaluation in Counseling and Development, 37, 163-183. https://doi.org/10.1080/07481756.2004.11909758

Gamst, G., Arellano-Morales, L., Meyers, L. S., Tolstoy, B., Garcia, S., Sjobeck, G., Blair, R., \& Casas, M. (2018). Development and validation of the Latina American Shifting Scale (LASS). (2018). Gender Issues. https://doi.org/10.1007/s12147-018-9225-1

Ghani, N. (2016). Pakistani migrants in the United States: The interplay of ethnic identity and ethnic retention. American International Journal of Social Science, 5(4), 17-26.

Ghaffar-Kucher, A. (2011). The religification of Pakistani-American youth. American Educational Research Journal, 49(1), 30-52. https://doi. org/10.3102/0002831211414858

Ghorbani, N., Watson, P. J., Ghramaleki, A., Morris, R. J., \& Hood, R. W. (2000). Muslim attitudes towards religion scale: Factors, validity and complexity of relationships with mental health in Iran. Mental Health, Religion and Culture, 3(2), 125132. https://doi.org/10.1080/713685603

Grewal, I., Nazroo, J., Bajekal, M., Blane, D., \& Lewis, J. (2004). Influences on quality of life: A qualitative investigation of ethnic differences among older people in England. Journal of Ethnic and Migration Studies, 30(4), 737-761. https://doi.org/10.1 080/13691830410001699595

Hackney, C. H., \& Sanders, G. S. (2003). Religiosity and mental health: A meta-analysis of recent studies. Journal for the Scientific Study of Religion, 42(1), 43-55. https:// doi.org/10.1111/1468-5906.t01-1-00160

Henning, M. A., Krageloh, C., Thompson, A., Sisley, R., Doherty, I., \& Hawken, S. J. (2015). Religious affiliation, quality of life and academic performance: New Zealand medical students. Journal of Religious Health, 54(1), 3-19. https://doi. org/10.1007/s10943-013-9769-Z

Herzig, B. A., Roysircar, G., Kosyluk, K. A., \& Corrigan, P. W. (2013). American Muslim college students: The impact of religiousness and stigma on active coping. Journal of Muslim Mental Health,7(1), 33-42. https://doi.org/10.3998/ jmmh.10381607.0007.103

Hofmann, S. G., Wu, J. Q., \& Boettcher, H. (2014). Effects of cognitive-behavioral ther- 
apy for anxiety disorders on quality of life: A meta-analysis. Journal of Consulting and Clinical Psychology, 82(3), 375-391. https://doi.org/10.1037/a0035491

Holdcroft, B. (2006). What is religiosity? Catholic Education: A Journal of Inquiry and Practice, 10(1), 89-103. https://doi.org/10.15365/joce.1001082013

Hussain, Y., \& Bagguley, P. (2005). Citizenship, ethnicity, and identity: British Pakistanis after the 2001 riots. Sociology, 39(3), 407-425. https://doi. org/10.1177/0038038505052493

Ibrahim, F., \& Heuer, J. R. (2013). The assessment, diagnosis, and treatment of mental disorders among Muslims. In F. A. Paniagua \& A.-M. Yamada Eds.), Handbook of multicultural mental health: Assessment and treatment of diverse populations ( $2^{\text {nd }}$ ed.), (pp. 367-387). San Diego, CA: Academic Press. https://doi.org/10.1016/B9780-12-394420-7.00019-9

Ibrahim, F., Ohnishi, H., \& Sandhu, D. S. (1997). Asian American identity development: A culture specific model for South Asian Americans. Journal of Multicultural Counseling and Development, 25(1), 34-50. https://doi.org/10.1002/j.21611912.1997.tb00314.x

Ismail, Z., \& Desmukh, S. (2012). Religiosity and psychological well-being. International Journal of Business and Social Science, 3(11), 20-28.

Jacobson, J. (1997). Religion and ethnicity: Dual and alternative sources of identity among young British Pakistanis. Ethnic and Racial Studies, 20(2), 238-256. https:// doi.org/10.1080/01419870.1997.9993960

Jibeen, T. (2011). Moderators of acculturative stress in Pakistani immigrants: The role of personal and social resources. International Journal of Intercultural Relations, 35(5), 523-533. https://doi.org/10.1016/j.ijintrel.2011.04.002

Johnson, J. C., Gamst, G., Meyers, L. S., Arellano-Morales, L., \& Shorter-Gooden, K. (2016). Development and validation of the African American Women's Shifting Scale (AAWSS). Cultural Diversity and Ethnic Minority Psychology, 22(1), 11-25. https://doi.org/10.1037/cdp0000039

Kanwal, H., \& Mustafa, N. (2016). Psychological well-being and quality of life among physically disabled and normal employees. Pakistan Armed Forces Medical Journal, 66(5), 710-714.

Keyser, V., Gamst, G., Meyers, L. S., Der-Karabetian, A., \& Morrow, G. (2015). Predictors of self-perceived cultural competence among children's mental health providers. Cultural Diversity and Ethnic Minority Psychology, 20(3), 324-335. https://doi. org/10.1037/a0035762

Khalid, R. (2011). Changes in perception of gender roles: Returned migrants. Pakistan Journal of Social and Clinical Psychology, 9, 16-20.

Khalid, R., \& Frieze, I. H. (2004). Measuring perceptions of gender roles: The IAWS for Pakistanis and U. S. immigrant populations. Sex Roles, 51(5), 293-300. https://doi. org/10.1023/B:SERS.0000046613.99273.22

Kline, R. B. (2015). Principles and practice of structural equation modeling $\left(4^{\text {th }} \mathrm{ed}\right.$.). New York, NY: Guilford Press.

Little, T. D., Cunningham, W. A., Shahar, G., \& Widaman, K. F. (2002). To parcel or not to parcel: Exploring the question, weighing the merits. Structural Equation Modeling, 9, 151-173. https://doi.org/10.1207/S15328007SEM0902_1

Little, T. D., Rhemtulla, M., Gibson, K., \& Schoemann, A. M. (2013). Why the items versus parcels controversy needn't be one. Psychological Methods, 18, 285-300. https://doi.org/10.1037/a0033266 
Matsunaga, M. (2008). Item parceling in structural equation modeling: A primer. Communication Methods and Measures, 2, 260-293. https://doi. org/10.1080/19312450802458935

McHugh, M. C., \& Frieze, I. H. (1997). The measurement of gender-role attitudes: A review and commentary. Psychology of Women Quarterly, 21, 1-16. https://doi. org/10.1111/j.1471-6402.1997.tb00097.x

Peek, L. (2005). Becoming Muslim: The development of a religious identity. Sociology of Religion, 66(3), 215-242. https://doi.org/10.2307/4153097

Pew Research Center (2017). Pakistanis in the U.S. fact sheet: Pakistani population in the U.S., 2000-2015. http://www.pewsocialtrends.org/fact-sheet/asian-americanspakistanis-in-the-u-s/

Phinney, J. S., \& Ong, A. (2007). Conceptualization and measurement of ethnic identity: Current status and future directions. Journal of Counseling Psychology, 54(3), 271-281. https://doi.org/10.1037/0022-0167.54.3.271

Platsidou, M. (2012). Life satisfaction in adults: The effect of religiosity, worry, and perceived physical health state. In A. Efklides \& D. Moraitou (Eds.), A positive psychology perspective on quality of life (pp. 87-106). New York, NY: Springer. https:// doi.org/10.1007/978-94-007-4963-4_6

Qureshi, R., \& Pacquiao, D. F. (2013). Ethnographic study of experiences of Pakistani women immigrants with pregnancy, birthing, and postpartum care in the United States and Pakistan. Journal of Transcultural Nursing, 24(4), 355-362. https://doi. org/10.1177/1043659613493438

Raza, A., \& Murad, H. S. (2010). Gender gap in Pakistan: A socio-demographic analysis. International Journal of Social Economics, 37(7), 541-557. https://doi. org/10.1108/03068291011055478

Shahzadi, N., Qureshi, M., \& Islam, M. (2012). Effect of domestic violence on women psychology in Pakistan. Language in India, 12(10), 293-311.

Spence, J. T., Helmreich, R. L., \& Stapp, J. (1974). The Personal Attributes Questionnaire: A measure of sex role stereotypes and masculinity-femininity. JSAS Catalog of Selected Documents in Psychology, 4, 43. https://doi.org/10.1037/t02466-000

Suhail, K., \& Chaudhry, H. (2004). Predictors of subjective well-being in an eastern Muslim culture. Journal of Social \& Clinical Psychology, 23(3), 359-376. https://doi. org/10.1521/jscp.23.3.359.35451

Trimble, J. E., Helms, J. E., \& Root, M. P. P. (2003). Social and psychological perspectives on ethnic and racial identity. In G. Bernal, J. E. Trimble, A. K. Burlew, \& F. T. L. Leong (Eds.), Handbook of racial \& ethnic minority psychology (pp. 239-275). Thousand Oaks, CA: SAGE. https://doi.org/10.4135/9781412976008.n13

United States Department of State (2012). Pakistan 2012 international religious freedom report. Retrieved from http://www.state.gov/documents/organization/208650.pdf

Veenhoven, R. (1996). The study of life satisfaction. In W. E. Saris, R. Veenhoven, A. C. Scherpenzeel, \& B. Bunting (Eds.), A comparative study of life satisfaction with life in Europe (pp. 11-48). Budapest, Hungary: Eötvös University Press.

Wilde, A., \& Joseph, S. (1997). Religiosity and personality in a Moslem context. Personality and Individual Differences, 23(5), 899-900. https://doi.org/10.1016/S01918869(97)00098-6

Zakar, R., Zakar, M., \& Krämer, A. (2012). Voices of strength and struggle: Women's coping strategies against spousal violence in Pakistan. Journal of Interpersonal Violence, 27(16), 3268-3298. https://doi.org/10.1177/0886260512441257 